\title{
A Prospective Assessment of Autoimmune Sensitization of Hypertensive Patients on Antihypertensive Therapy: A Hospital Based Study
}

\section{Ogbonna Collins Nwabuko1,2*, Innocent ljezie Chukwuonye ${ }^{3}$ and May Gogo Nwabuko}

${ }^{1}$ Department of Hematology, Federal Medical Center, Umuahia, Abia State, Nigeria

${ }^{2}$ Department of Hematology, College of Health Science, Abia State University, Aba, Abia State, Nigeria

${ }^{3}$ Division of Nephrology, Department of Internal Medicine, Federal Medical Center, Umuahia, Abia State University, Abia State, Nigeria

${ }^{4}$ Department of Pathology, Braithwaith Memorial Specialist Hospital, Port Harcourt, Rivers State, Nigeria

\begin{abstract}
Background: Autoimmune sensitization by antihypertensive drugs is an emerging cause of morbidity and mortality among hypertensive on antihypertensive therapy and little is known about it in our environment. The aim of this study is to evaluate autoimmune sensitization among hypertensive patients on antihypertensive therapy using DAT (Direct Antiglobulin test or Direct Coomb's test) and Hemoglobin concentration.
\end{abstract}

Materials and method: This was a 4-month single center prospective study of 60 hypertensive patients on antihypertensive drugs and 40 age and sex matched control who were attending Cardiology Clinic in BMSH Port Harcourt. Hemoglobin concentration, Packed Cell Volume (PCV) and DAT were obtained using Cyanmethemoglobin, Microhematrocrit and Conventional tube methods respectively, while other clinical data were obtained using structured questionnaires. Data analysis was by SPSS version 20.

Results: There was no significant change in the mean hemoglobin concentration/PCV of the hypertensive patients on therapy and their control counterparts ( $13.4 \mathrm{~g} / \mathrm{dL} / 40.7 \%$ versus $13.4 \mathrm{~g} / \mathrm{dL} / 40.7 \%$; $p>0.05$ ). The DAT in the hypertensive patients on therapy and their hypertensive control counterparts was negative.

Conclusion: Although antihypertensive drugs have the tendency of instigating immune sensitization of red blood cells, this was not demonstrated from this study. However, further studies with a larger sample size can improve validity of the result.

Keywords: Assessment; Autoimmune sensitivity; Hypertension; Anti-hypertensive therapy; Nigeria

\section{Introduction}

The World Health Organization (WHO)/International Society of Hypertension (ISH) guidelines, defines "hypertension" as systolic Blood Pressure (SBP) greater or equal to $140 \mathrm{mmHg}$ and/or diastolic BP (DBP) greater or equal to $90 \mathrm{mmHg}$ and/or self-reported treatment of hypertension with antihypertensive medication taken in the past two weeks [1-25]. It is the commonest non-communicable disease and the leading cause of death in the world $[14,15,24]$. The American Society of Hypertension (ASH) simply describes it as a silent killer, and global public health crisis [11,23]. About one billion adult population $(\approx 26 \%)$ was living with hypertension globally as of the year 2000 [15]. It is predicted to rise to 1.5 billion by the year 2025 [3]. The use of drugs has been recommended in the treatment of hypertension alongside lifestyle measures [12]. A number of different classes of drugs are available to help lower pressure. They include diuretics (including frusemide, thiazides, and spironolactone), alpha or betaadrenergic receptors blockers, and calcium-channel blockers, centrally acting alpha agonists (methyl dopamine), vasodilators, angiotensinconverting enzyme (ACE inhibitors) and angiotensin receptor blockers [12]. Previous studies have shown association between autoimmune sensitization and hypertension treatment with antihypertensive drugs. In one study, there were increased circulating autoantibodies in patients with hypertension [20]. Autoimmune sensitization in this context is the binding of antibodies to cells such as erythrocytes prior to performing an immunological test such as complement-fixation or anti-human globulin test [1]. In hypertensive state, autoimmune sensitization entails binding of antibody or soluble antigen chemically or by adsorption to appropriate biological entity such as erythrocyte or particle made of gelatin or latex for passive aggregation. Another study revealed that increase autoimmune sensitization in addition with increase in antinuclear antibodies is consistent with systemic autoimmune disorders in patients with essential hypertension [17] Antihypertensive drugs can trigger drug induced hemolytic anemia through autoimmune sensitization determined via DAT. Druginduced immune hemolytic anemia (DIIHA) is an extremely rare blood disorder typically seen in hypertensive patients $[4,10]$. It occurs when a drug stimulates the body's immune system to mistakenly attack its own red blood cells. DIIHA is a rare condition with an estimated incidence of approximately one case per million inhabitants per year [19]. Immune antibodies which require the presence of the drug to produce a positive DAT result may react with red cells when the drug is bound to them (drug adsorption mechanism) or when immune complexes are produced between the drug and the antibody, which is absorbed on to the red cell surface where complement is fixed and activated, leading to acute intravascular hemolysis [13]. The three stages required to make diagnosis of DIIHA in hypertensive patients include:

*Corresponding author: Nwabuko OC, Department of Hematology, Federa Medical Center, Aba Road, PMB 7001, Umuahia, Abia State, Nigeria, Tel: +234 80 3704 6537; E-mail: ogbollins2002@yahoo.com

Received September 29, 2017; Accepted October 10, 2017; Published Octobe 25, 2017

Citation: Nwabuko OC, Chukwuonye II, Nwabuko MG (2017) A Prospective Assessment of Autoimmune Sensitization of Hypertensive Patients on Antihypertensive Therapy: A Hospital Based Study. J Blood Lymph 7: 183. doi: 10.4172/2165-7831.1000183

Copyright: (C) 2017 Nwabuko OC, et al. This is an open-access article distributed under the terms of the Creative Commons Attribution License, which permits unrestricted use, distribution, and reproduction in any medium, provided the original author and source are credited. 
i) careful drug history; ii) diagnosis of a DAT-positive hemolytic anemia; and iii) serological demonstration of drug-specific antibody, which interacts with red cells. Some antihypertensive drugs such as alpha methyldopa and other centrally acting alpha agonists can cause autoimmune sensitization leading to DIIHA [22]. These occurrences and their possible negative impact on hypertensive patients stimulated the zeal to carry out this study.

\section{Materials and Methods}

This was a 4-month prospective study carried out from April 2016 to July 2016 at Braithwaite Memorial Specialist Hospital (BMSH), a 200-bed hospital located in Port Harcourt, Rivers State, Nigeria. Ethical clearance was obtained from the ethics committee of BMSH in keeping with the guidelines of the declaration of Helsinki (1964) and Good Clinical Practice. Written informed consent was obtained from the patients before enrollment and the patients' identities were kept confidential. Port Harcourt is a typical coastal zone located in the oilrich Niger Delta region of Nigeria. BMSH serves as a referral hospital for inhabitants of Rivers state and other neighboring states of Niger Delta region which account for $>20 \%$ of Nigerian population based on 1991 population census [8]. Facilities in BMSH were used for the analysis within the study period. Standard venipuncture technique was used to collect $3 \mathrm{~mL}$ of blood from each participant into EDTA anticoagulant bottles for the analysis. Each blood sample was properly mixed with the anticoagulant to avoid clotting before the analysis. Blood Pressure was measured using Digital Automatic Blood Pressure Monitor. Three blood-pressure readings were taken at an interval of two minutes. Thereafter, the average blood pressure for the second and third readings (systolic/diastolic) was used. DAT was based on coating of the red cells with complement or IgG antibodies which do not agglutinate directly when centrifuged. These cells are said to be sensitized with $\operatorname{IgG}$ or complement. In order for agglutination to occur an additional antibody, which reacts with the $\mathrm{F}_{\mathrm{C}}$ portion of the IgG antibody, or with the $\mathrm{C} 3 \mathrm{~b}$ or C3d component of complement, must be added to the system. This will form a "bridge" between the antibodies or complement coating the red cells, causing agglutination. Monoclonal Anti-human globulin (AHG) was used to detect the presence of antibody on red cells formed due to sensitization in-vivo [23]. This was done washing the patients' red cells three times with saline to prepare a $5 \%$ suspension. Thereafter, 0.2 $\mathrm{mL}$ of the washed red cells was added to $0.4 \mathrm{~mL}$ ( 1 drop) of AHG in a clean test tube. The mixture was allowed to stand for 10-15 minutes and centrifuged at $1000 \mathrm{~g}$ for 15 seconds. After this, the tube was examined for agglutination (clump of cells) macroscopically and microscopically. A negative result indicates "no agglutination was seen" while a positive result indicates "agglutination was seen". Determination of Packed Cell Volume was by Microhaematocrit method using capillary tube while haemoglobin estimation was by Cyan methaemoglobin method as described by Bain et al [2].

\section{Data Analysis}

Data obtained from this study were analyzed using Statistical Package for the Social Sciences (SPSS) version 20. All statistical data were entered and analyzed using SPSS statistical software version 20.0 (IBM Corporation, Armonk, NY, USA). P $<0.05$ was considered statistically significant.

\section{Results}

A total of 60 patients comprising of 30 males and 30 females clinically diagnosed to be hypertensive and on antihypertensive drugs and 40 (20 males and 20 females) age and sex matched control were recruited in this study. Both hypertensive patients on drugs and those not on drugs were aged between 45 and 75 years and were either inpatients or out-patients of medical clinic of the hospital. The mean ages of female hypertensive patients on anti-hypertensive drugs and their counterparts that were not on the drugs were $45 \pm 7$ years and $35 \pm 9$ years respectively. There was a statistical significant difference between the systolic and diastolic blood pressures of the two groups of patients $(\mathrm{p}<0.05)$. However, their hemoglobin concentrations and packed cell volumes (PCVs) did not differ significantly $(\mathrm{p}>0.05)$. The mean systolic $\mathrm{BP}$ of female hypertensive patients on therapy and the mean diastolic $\mathrm{BP}$ of hypertensive patients who were not on therapy were higher compared to that of hypertensive patients who were not on therapy and those who were on therapy respectively $(127 \mathrm{mmHg} v s .124 \mathrm{mmHg}$ and $80 \mathrm{mmHg}$ vs. $84 \mathrm{mmHg}$ ) (Table 1). The mean ages of male hypertensive patients on anti-hypertensive drugs and their counterparts that were not on the drugs were $45 \pm 7$ years and $35 \pm 9$ years respectively. There was a statistical difference in their systolic blood pressures, however, there was no statistical difference in the diastolic blood pressures, hemoglobin concentrations/PCVs of the hypertensive subjects on antihypertensive and those not on antihypertensive. The mean systolic and diastolic BPs of male hypertensive patients on therapy were higher than that of male hypertensive counterparts who were not on therapy (129 $\mathrm{mmHg}$ vs. $124 \mathrm{mmHg}$ and $88 \mathrm{mmHg}$ vs. $81 \mathrm{mmHg}$ ), respectively (Table 2). The mean systolic and diastolic BPs of Male hypertensive

\begin{tabular}{|c|c|c|c|}
\hline Parameters (Mean \pm SD) & Hypertensive Patients on Drugs (Test) & $\begin{array}{c}\text { Hypertensive Patients Not on Drugs } \\
\text { (Control) }\end{array}$ & p-Value \\
\hline Age (Years) & $45 \pm 7$ & $35 \pm 9$ & $<0.05(\mathrm{~S})$ \\
\hline Systolic BP (mmHg) & $127 \pm 10$ & $124 \pm 14$ & $<0.05(\mathrm{~S})$ \\
\hline Diastolic BP (mmHg) & $80 \pm 8$ & $84 \pm 10$ & $>0.05(\mathrm{NS})$ \\
\hline Hemoglobin (g/dL) & $12.8 \pm 0.8$ & $12.6 \pm 1.0$ & $>0.05($ NS) \\
\hline
\end{tabular}

NS: Not Significant; S: Significant.

Table 1: Comparison of BP and Hemoglobin Parameters of Female Hypertensive Patients on Drugs and not on drugs

\begin{tabular}{|c|c|c|c|}
\hline Parameter (Mean \pm SD) & Hypertensive Patients on drugs & Hypertensive Patients Not on drugs & $35 \pm 9$ \\
\hline Age (years) & $45 \pm 7$ & $124 \pm 13.5$ \\
\hline Systolic BP $(\mathrm{mmHg})$ & $129 \pm 12$ & $81 \pm 10$ & $<0.05$ (S) \\
\hline Diastolic BP (mmHg) & $88 \pm 10$ & $13.4 \pm 1.0$ & $>0.05(\mathrm{NS})$ \\
\hline Hemoglobin (g/dL) & $13.4 \pm 0.8$ & $40.7 \pm 3.5$ \\
\hline Packed Cell Volume (\%) & $40.0 \pm 2.5$ & $>0.05$ (NS) & $>0.05$ (S) \\
\hline
\end{tabular}

S: Significant; NS: Not Significant.

Table 2: Comparison of Hematological Parameters and BPs of Male Hypertensive Patients on Drugs and the Male Hypertensive Patients Not on Drugs. 
patients on therapy were significantly higher than that of Female patients on therapy $(129 \mathrm{mmHg}$ vs. $127 \mathrm{mmHg}$ and $88 \mathrm{mmHg}$ vs. 80 $\mathrm{mmHg}$ ) respectively. The mean Hemoglobin concentration/PCV of the Male hypertensive patients on therapy was higher than that of their Female counterparts $(13.4 \mathrm{~g} / \mathrm{dL} / 40 \%$ vs. $12.6 \mathrm{~g} / \mathrm{dL} / 38.7 \%)$, respectively (Table 3). The mean hemoglobin concentration/PCV of both Female hypertensive patients on therapy were relatively higher than that of their Female counterparts who were not on therapy $(12.8 \mathrm{~g} / \mathrm{dL} / 38.7 \%$ vs. $12.6 \mathrm{~g} / \mathrm{dL}$ vs. $37.9 \%)$. However, there was no change in the mean hemoglobin concentration/PCV of the Male hypertensive patients on therapy and the Male counterparts who were not on therapy (13.4g/ dL/40.7\% vs. $13.4 \mathrm{~g} / \mathrm{dL} / 40.7 \%)$. The Direct Anti-human globulin tests (DAT) on both Male and Female hypertensive patients on therapy and those who were not on therapy were negative (Table 4). The antihypertensive drugs taken by the patients were diuretics (loop diuretics such as frusemide), centrally acting alpha-agonists (such as methyl dopa), alpha-adrenergic blockers (such as prazosin), betaadrenergic blockers (such as acebutolol, atenolol and propranolol), calcium channel blockers (dihydropyridines such as nifedipine and amlodipine), angiotensin-converting enzyme inhibitor (such as lisinopril or enalapril) and angiotensin II receptor blockers (ARBs) (such as olmesartan and valsartan).

\section{Discussion}

The comparison of means via descriptive statistical analysis of the blood pressures and hematological parameters in hypertensive patients on anti-hypertensive therapies and hypertensive patients who were not on anti-hypertensive therapy revealed that blood pressure varies among hypertensive patients and with respect to gender but with little or no statistical significance and putting into consideration the antihypertensive drugs taken. This study showed that the mean systolic $\mathrm{BP}$ of both male and female and diastolic BP of male hypertensive patients on anti-hypertensive therapies were higher than their hypertensive counterparts who were not on therapy. This could be due to poor drug compliance. It has been estimated that within the first year of treatment $16-50 \%$ of hypertensive discontinue or missed the doses of their anti-hypertensive medications [9]. Epidemiological studies have shown that drug-treated hypertensive have higher BPs than age-, gender- and body mass index-matched normotensives. Possible reasons could be the use of drugs with inadequate BP lowering effects. In our society, the interruption or discontinuation of antihypertensive medications could be due to high health care costs, due to inflation, or poverty due to high rate of unemployment in the country. Taking a critical look at the autoimmune sensitization determined via direct anti-human globulin test (DAT or direct coombs test), no significant result was obtained with respect to the hypertensive patients taking antihypertensive drugs and the hypertensive who were not on medication. Both the male and female gender population showed no positivity to DAT $(0 \%)$. This was lower when compared to that recorded in United States [16] where autoimmunity/adverse antihypertensive drug reactions account for 6 to 15 percent of hospitalized hypertensive patients. They have been described as the most common iatrogenic illness complicating 5 to 15 percent of therapeutic drug courses [6]. Previous studies have shown that some antihypertensive drugs bring about their BP control effect by reducing some inflammatory biomarkers, thus highlighting important clinical implications for hypertension related cardiovascular complications. In a study [7] the beneficial cardiovascular effects of angiotensin II receptor antagonists could be due to their action in reducing inflammatory biomarkers in hypertensive subjects. They were said to effect reduction of vascular micro inflammation in patients with antihypertensive by as early as 6 weeks of therapy. This result was subsequently confirmed in a clinical trial including 276 essential hypertensive patients randomized to olmesartan, amlodipine or a single pill containing an olmesartan/ amlodipine combination for 12 months [5]. The study showed that olmesartan/amlodipine significantly decreased C-reactive protein level and that their combination was more effective than single agent therapy (monotherapy) in reducing inflammatory biomarkers. Based on these findings, they established that future prospective and properly designed clinical studies are strongly needed to shed some light on what class of antihypertensive drugs could be beneficial not only for BP control but for inflammation-related cardiovascular complications as well. This study showed that the mean hemoglobin concentration/ PCV of hypertensive patients on antihypertensive drugs (13.1 g/ $\mathrm{dL} / 40 \%)$ and those not on the drugs $(13.0 \mathrm{~g} / \mathrm{dL} / 40 \%)$ were essentially normal. This shows that no drug-induced immune hemolytic anemia (DIIHA) was detected among the study population. DIIHA is one way of demonstrating autoimmune sensitivity by antihypertensive drugs. Drugs such as Penicillin, cephalosporin's and methyldopa, are good at causing DIIHA [22]. Although this is a rare condition, it has an estimated incidence of approximately one case per million inhabitants per year [19]. DIIHA may be very severe and life-threatening when it occurs [10]. There are three mechanisms that can give rise to DIIHA. They include autoimmune sensitization, immune antibodies and immune complex mechanisms. The absence of DIIHA in our study may be in keeping with no autoimmune sensitization by the antihypertensive drugs used by the study population [13].

\section{Conclusion}

Although antihypertensive drugs have the tendency of causing

\begin{tabular}{|c|c|c|c|}
\hline Parameter (Mean \pm SD) & Females & Males \\
\hline Age (years) & $45 \pm 7$ & $45 \pm 7$ \\
\hline Systolic BP $(\mathrm{mm} \mathrm{Hg})$ & $127 \pm 10$ & $129 \pm 12$ & $<0.05$ (S) \\
\hline Diastolic BP (mm Hg) & $80 \pm 8$ & $88 \pm 12$ & $>0.05$ (NS) \\
\hline Hemoglobin (g/dL) & $13.4 \pm 0.8$ & $13.4 \pm 1.0$ & $>0.05$ (NS) \\
\hline PCV (\%) & $40.0 \pm 2.5$ & $40.7 \pm 3.5$ \\
\hline
\end{tabular}

S: Significant; NS: Not Significant.

Table 3: Comparison of Hematological Parameters and BPs of Male and Females Hypertensive Patients on Drugs.

\begin{tabular}{|c|c|c|c|c|c|}
\hline Gender & $\begin{array}{c}\text { No of Hypertensive } \\
\text { Patients on drugs }\end{array}$ & No of Positive DAT & Percentage (\%) & $\begin{array}{c}\text { No of Hypertensive Patients } \\
\text { Not on Drugs }\end{array}$ & No of Positive DAP \\
\hline Males & 30 & 0 & 0 & 10 & 0 \\
\hline Females & 30 & 0 & 0 & 10 & 0 \\
\hline Total & $\mathbf{6 0}$ & $\mathbf{0}$ & $\mathbf{2 0}$ & 0 \\
\hline
\end{tabular}

Table 4: Percentage distribution of DAT test Results for Hypertensive Patients. 
Citation: Nwabuko OC, Chukwuonye II, Nwabuko MG (2017) A Prospective Assessment of Autoimmune Sensitization of Hypertensive Patients on Antihypertensive Therapy: A Hospital Based Study. J Blood Lymph 7: 183. doi: 10.4172/2165-7831.1000183

immune sensitization of red blood cells with the possibility of triggering anemia, this was however not demonstrated in our study, probably because of the small sample size. Hypertensive patients should, therefore, be educated about the possible side effects of the drugs they are taking, and discouraged from engaging in self-medication. Also, more studies with a larger sample size should be carried to shade more light on autoimmune sensitization of antihypertensive drugs in black Africans. Evidence on the causal link between immunity and hypertension in humans is limited. As a future research line, clinical trials testing immunosuppressant drugs should be evaluated on their effect on BP.

\section{Limitations}

Higher number of participants can improve validity of further studies. The names of the various anti-hypertensive drugs used to treat the patients were not properly documented so as to individualize the effects of each of the anti-hypertensive drug used. Further studies should take this into consideration.

\section{Acknowledgements}

The authors wish to thank the management and the departments of Hematology and Internal Medicine of Braithwait Memorial Specialist Hospital, Port Harcourt, Federal Medical Center, Umuahia, and Abia State University Teaching Hospital, Aba Campus, Nigeria for creating enabling environment for this research work.

\section{Disclosure}

The authors report no conflicts of interest in this work.

\section{References}

1. Anderson OK, Lingman M (2004) Prediction of future hypertension by causa blood pressure or invasive hemodynamics? A 30-year follow-up study. Blood Pressure 13: 350-354.

2. Bain BJ, Lewis SM, Bate I (2008) Basic Haematological Technique, In: Lewis SM, Bain BJ editors. Bates I. Decie and Lewis Practical Haematology $\left(10^{\text {th }}\right.$ edn.), Churchill Livingstone. Philadelphia, pp: 25-57.

3. Center for Disease and Prevention (2015) Global Health Fact Sheet

4. Rahimi K, Emdin CA, MacMahon S (2015) The Epidemiology of Blood Pressure and Its Worldwide Management. Circulation Research 116: 925-936.

5. Derosa G, Bonaventure A, Romano D, Bianchi L, Fogari E, et al. (2014) Effects of Enalapril/Lercanidipine Combination on some Emerging Biomarkers in Cardiovascular Risk Stratification in Hypertensive Patients. J Clin Pharm Ther 39: 277-85.

6. Ditto B, Campbell TS, Seguin JR, Assad JM, (2002) Longitudinal study of pain sensitivity and Blood pressure. Health Psychology 21: 594-600.

7. Fisher ND, Williams GH (2005) Hypertensive vascular disease. In: Kasper DL, Braunwald E, Fauci AS editors. Harrison's Principles of Internal Medicine (16 edn.), New York, NY: McGram-Hill, pp: 1463-1481.

8. Federal Republic of Nigeria (1991) Niger Delta Regional Development Master Plan.

9. Flack JM, Novikov SV, Ferrario CM (1996) Benefits of adherence to antihypertensive drug therapy. European Heart Journal 17: 16-20.

10. Gharib C, Rial MO, Joanny C, Milon H, Joanny C (2002) Spontaneous baroreflex Sensitivity, Cardiovascular risk in hypertension. J Hypertens 20: 935-44.

11. Giles TD, Berk BC, Black HR, Cohn JN, Kostis JB, et al. (2005) Expanding the definition and classification of Hypertension. J Clin Hypertens 7: 505-512.

12. George L, Bakris MD (2015) Treatment of Hypertension. American Heart Association Journals.

13. Hall JE, Hildebrandt DA, Kuo J (2001) Obesity, hypertension: Role of leptin and sympathetic nervous system. Am J Hypertens 14: 103S-115S.

14. Kearney PM, Whelton M, Reynolds K, Whelton PK, He J (2004) Worldwide prevalence of hypertension: a systematic review. Journal of Hypertension 22 $11-19$.
15. Kearney PM, Whelton M, Reynolds K, Muntner P, Whelton PK et al. (2005) Global burden of hypertension: Analysis of worldwide data. Lancet 365: 217-23

16. Lazarou J, Pomeranz BH, Corey PN (2000) Beyond the evidence of the New Hypertension Guidelines. Blood Pressure Measurement 6: 6.

17. Mathis KW, Wallace K, Wasson K, Masterson C, Ryan M (2012) T cells promote the progression of hypertension and renal injury during systemic lupus erythematosus. Hypertension 160: 174-179.

18. National Heart, Lung, Blood Institute (2015) "How Is High Blood Pressure Treated?"

19. Petz LD, Garratty G (2004) Immune Hemolytic Anemias ( $2^{\text {nd }}$ edn.), Philadelphia: Churchil Livingstone 261-317.

20. Pugh RN, Murray-Lyon IM, Dawson JL, Pietroni MC, Williams R (2000) Transection of the esophagus for bleeding oesophageal varices. $\mathrm{Br}$ Journal of Surgery 60: 646-649.

21. Rodriguez-Cruz E, Ettinger LM (2015) Hypertension. Medscape.

22. Sarkar RS, Philip J, Mallhi RS, Neelesh J (2012) Drug-induced immune hemolytic anemia (Direct Antiglobulin Test Positive). Medical Journal Armed Forces India 69: 190-192.

23. Thomas DG, Materson BJ, Cohn JN, Kostis BJ (2009) Definition and Classification of Hypertension: An Update. The Journal of Clinical Hypertension 11: 611-614.

24. Ulasi II, ljoma CK, Onwubere BJC, Arodiwe E, Onodugo O, et al. (2011) High Prevalence and Low Awareness of Hypertension in a Market Population in Enugu, Nigeria. International Journal of Hypertension 2011: 5.

25. Whitworth JA, World Health Organization, International Society of Hypertension Writing Group (2003) 2003 World Health Organization (WHO)/International Society of Hypertension (ISH) Statement on management of hypertension. $J$ Hypertension 21: 1983-92. 